\title{
Development of a total colonoscopy rat model with endoscopic submucosal injection of the cecal wall
}

\author{
C. Haughn, ${ }^{1}$ M. Uchal, ${ }^{2}$ Y. Raftopoulos, ${ }^{1}$ S. Rossi, ${ }^{1}$ T. Santucci, ${ }^{1}$ M. Torpey, ${ }^{1}$ A. Pollice, ${ }^{1}$ Y. Yavuz, ${ }^{3}$ R. Marvik, ${ }^{3}$ \\ R. Bergamaschi ${ }^{1}$ \\ ${ }^{1}$ Minimally Invasive Surgery Center, Allegheny General Hospital, 320 East North Avenue, Pittsburgh, PA 15212, USA \\ ${ }^{2}$ Department of Research and Development, Forde Health System, Tefre Veg, Forde, 6807, Norway \\ ${ }^{3}$ National Center for Advanced Laparoscopic Surgery, St. Olav Hospital, Olav Kyrres Gate 17, Trondheim, N-7006, Norway
}

[Surg Endosc (2006) 20: 270, DOI: 10.1007/s00464-005-0088-7]

The spelling of one of the authors, Y. Yavuz, was published incorrectly, and it is corrected here. 